\title{
Student wellbeing for those with profound intellectual and multiple disabilities: same, or same but different?
}

\author{
Gordon Lyons and Michele Cassebohm \\ School of Education \\ University of Newcastle \\ Australia
}

\begin{abstract}
The nature of student wellbeing, although now subject to some consensus, continues to engender debate. To improve student wellbeing, widely regarded to be an overarching non-academic outcome of schooling, it is generally argued that we must come to a consensual conceptualisation of wellbeing in order to define it operationally and make it measurable. The new Australian Curriculum puts forward common educational curriculum and outcomes for all students - including those outcomes implicitly and explicitly related to student wellbeing. For students with profound intellectual and multiple disabilities this is, we argue, philosophically and practically problematic. We put forward a research-based conceptualisation of subjective wellbeing for these students and recommend this as a basis for a continuing research agenda to improve their wellbeing.
\end{abstract}

\section{Introduction}

The nature of student wellbeing, although now subject to some consensus, continues to engender debate (Noble and Wyatt 2008). To improve student wellbeing, widely agreed to be an overarching 'non-academic' outcome of schooling (Fraillon 2004), it is generally argued that we must first come to a consensual conceptualisation of wellbeing, then define it operationally, and then make it measureable (Anderson 2004). Historically school systems have seen it as part of their role to support, guide and encourage students' intra- and interpersonal aesthetic, physical and moral growth and development (Hamilton 2004). This role goes beyond the academic imperative of school education and, in collaboration with families and communities, schools have sought to develop students into healthy, well-rounded, engaged citizens 
(Noble and Wyatt 2008). Indeed improved outcomes in all aspects of student wellbeing are positively associated with improved outcomes in all other aspects of schooling (Fraillon 2004).

The Australian government has sought to clarify and formalise these broader goals of schooling (Fraillon 2004). The 2008 Melbourne Declaration on Educational Goals for Young Australians is authoritative. These goals combine academic and non-academic outcomes for schooling, although debate continues over whether this distinction is meaningful (Anderson 2004). Notwithstanding historical debates about the choice, measurement and improvement of academic outcomes (Killen 2005), similarly contentious but more recent debates have emerged about the conceptualisation, definition, measurement and improvement of the non-academic outcomes of schooling (Forster 2004; Noble and Wyatt 2008).

Academic schooling outcomes are generally defined in curriculum and syllabus documents, and assessment documents explain how they are measured and improved. Non-academic outcomes are less clearly defined, explicated and operationalised, and consensus about their measurement is also less evident (Fraillon 2004; Noble and Wyatt 2008). Four main unresolved issues remain: practical, meaningful data collection; opportunities for students to demonstrate achievements; the collection of evidence of student performance; and the high level of context dependency in student demonstration of outcomes. The challenge remains to demonstrate authentically how non-academic outcomes can be improved (Hamilton 2004).

Wellbeing has been widely conceptualised in terms of interrelated dimensions, elements and indicators like mental, physical, social, spiritual, economic, cognitive, psychological and emotional wellbeing (Pollard and Lee 2003). Pertinent constructs include: Ryan and Travis's (1998) 'wellness continuum'; Noble and Wyatt's (2008) 'wellbeing pathways'; Cummins' (2002) idea that wellbeing can fall into an unstable deficit state; and the notion that 'school community' is central to individual student wellbeing (Fraillon 2004). No definition of wellbeing prevails as definitions variously align with competing clinical psychological or functional perspectives (Cummins et al. 2010). Measurement also remains problematic (Fraillon 2004; Pollard and Lee 2003) particularly given that alternative outcome measures like understanding and behaviour are difficult to operationalise and draw inferences from (Forster 2004).

The Australian Curriculum will commence (at least in part) in 2012 (McGaw 2010). This is a curriculum for all school students and prescribes what all need to learn including common educational goals, core learning areas defined by requisite knowledge, skills and understandings, general capabilities and cross-curriculum priorities - including those implicitly and explicitly related to student wellbeing (Noble and Wyatt 2008). Although it is put forward as a common curriculum, substantial concerns have been expressed over its suitability for and relevance to students with 'special education needs' (Australian Association of Special Education 2011). According to the Australian Curriculum Assessment and Reporting Authority students with special education needs will be granted 'appropriate adjustments' in 
terms of content and assessment. Students with a 'significant intellectual disability', unable to benefit from these adjustments, will be provided with 'additional curriculum content and achievement standards' (Australian Curriculum Assessment and Reporting Authority 2010). At the time of writing though the authority has promulgated little information about this additional content and standards, and no rationale or explanation for how the common curriculum could be differentiated for this population of students.

Amongst those students with a 'significant intellectual disability' are those with profound intellectual and multiple disabilities (PIMD), as classified by the International Association for the Scientific Study of Intellectual Disabilities, the leading international professional organisation in the field. These students are

individuals with such profound cognitive disabilities that no existing standardized tests are applicable ... who often have profound neuromotor dysfunctions [and] sensory impairments. [They are] a physically very vulnerable group of persons with a high dependence on personal assistance for everyday tasks, 24 hours a day. (Nakken and Vlaskamp 2007)

PIMD is a heterogeneous classification but the profundity of these individuals' intellectual disabilities and the complexity of their widely varying concomitant sensory disabilities set them collectively apart from others.

Students with PIMD find learning more difficult than others and consequently their teachers find them most difficult to teach (Foreman and Arthur-Kelly 2005). Most students with PIMD lack formal language and usually rely on pre-symbolic, actionbased, idiosyncratic communicative gestures and utterances (Goode 1990). Consequently the establishment of relationships, intersubjectivity and meaningful communication are a priority for families, carers and service providers (Maes 2002). The nature of their education then is often very different from that of others (ArthurKelly et al. 2008) and its inherent challenges include philosophical, ethical and moral dimensions (Hewett 2009). These challenges affect curriculum, assessment and pedagogy (Bayliss 2005), which for these students are subject to continuing debate (Ware and Donnelly 2004).

So what is wellbeing for students with PIMD? This question of course is relevant to all students but it appears that the answer is somewhat different for those with PIMD (Lyons 2003; Petitpierre et al. 2007). Furthermore the means by which this question can be successfully investigated are substantially different (Lyons 2003).

\section{Conceptualising subjective wellbeing for children and young people with PIMD}

Conceptualising the nature of subjective wellbeing (SWB) for children and young people with PIMD is a difficult challenge (Goode 1984). The assumption that SWB is the same for all children and young people might be philosophically and ethically just but there is little research evidence to support it. Individuals with PIMD remain a relatively voiceless and disenfranchised group (Arthur-Kelly et al. 2008; Goldbart and Caton 2010) and practices designed to improve their quality of life, wellbeing 
and happiness have only a small research base. (See though, for example, Lancioni et al. 2002; Carnaby 2004; Singh et al. 2004; Hogg 2007; Petry, Maes and Vlaskamp 2009; Lyons 2010; Vos et al. 2010). Investigating this phenomenon calls for an atypical qualitative methodology simply because these individuals are unable to selfreport on their subjective lived experiences either because of their severe communication disabilities and/or their profound intellectual disabilities. A facilitative starting point for understanding this phenomenon is the literature on quality of life, life satisfaction (or SWB) and happiness, particularly as it applies to those with PIMD.

Since antiquity people have sought a life of 'quality'. Aristotle and Plato reflected extensively on eudemonia: happiness and living well. This pervasive pursuit of goodness of life, wellbeing, life satisfaction and quality of life endures notwithstanding diverse cultural interpretations and emphases. However there is little consensus about the terms happiness, life satisfaction, wellbeing and quality of life. Some theorists use the terms interchangeably whereas others regard quality of life as an encompassing multidimensional concept. SWB is an individual phenomenon that cannot be readily compared whereas quality of life is more closely related to standard of living; is measured using culturally appropriate social indicators; and is more about understanding and improving the standard of living of population groups. SWB is more about how individuals feel about their lives so pertinent research is about understanding the nature of personal feelings, cognitive appraisal and personality. To find out about another person's SWB researchers generally just ask how satisfied that person is with their life. This is usually done in person or by means of a questionnaire using a validated instrument or technique. Learning about another person's SWB is obviously problematic though when that person cannot readily communicate his or her (level of) satisfaction or wellbeing.

Scores of theories and models of quality of life and wellbeing have been proposed. However three prevalent and widely documented perspectives - the social indicators perspective, the psychological perspective and the goodness of fit/social policy perspective - are clearly identifiable in the literature (Schalock 1990; Halpern 1993). There are two principal schools of thought about quality of life and wellbeing measurement and assessment. The most widely supported upholds a holistic approach inclusive of both qualitative and quantitative approaches. The second argues that these concepts can be described but not measured. Felce and Perry (1996) argued that subjective evaluations of emotional wellbeing had been neglected in the intellectual disability literature because of the difficulties these persons had in communicating the nuances and complexities of abstract feelings and emotions. Hence quality of life and wellbeing assessment and measurement for individuals with PIMD brings about specific and complex challenges for researchers, decision makers and practitioners, and the nature of wellbeing and quality of life remains subject to continuing debate (Felce and Perry 2005).

\section{Investigating subjective wellbeing for children and young people with PIMD}

Lyons' theory of SWB for children and young people with PIMD was first described and explained in 2003 (Lyons 2003) and more recently in 2010 (Lyons and 
Cassebohm 2010). ${ }^{1}$ The original study investigated the nature of SWB for children and young people with PIMD and how others 'come to know' these children. It also informed the development of the Life Satisfaction Matrix, a procedure for improving the SWB of persons with PIMD (see Lyons 2005). The research problem was: Can the life satisfaction of children with PIMD be discerned? The primary research question was: What is life satisfaction for these children? The secondary research question was: How do we learn about the life satisfaction of these children? The participants consisted of 22 children, 12 with PIMD and 10 with high support needs, and 78 of their communication partners: their parents, other family members, paid carers, teachers, teacher aides and other professionals. Data was gathered from over 400 hours of participant observations and semi-structured interviews with these communication partners in school, home and community settings and a broad literature review.

Lyons described and explained the nature of SWB for these children and young people using a grounded theory consisting of a storyline and nineteen interrelated conceptual categories. The broader findings of the study were: the life satisfaction of children and young people with PIMD is discernible; there is strong evidence for the face validity of the Life Satisfaction Matrix and its four underlying principles; the research informed a continuing agenda investigating how communication partners come to know these children and young people; and the study contributed towards the small body of research into wellbeing and quality of life for persons with PIMD.

Given the substantial challenges inherent in this type of basic research (see e.g. Warren, Brady and Fey 2004), the choice of methods was critical to achieving rigorous and creditable outcomes. To conceptualise and understand a subjective phenomenon like SWB for children and young people with PIMD grounded theory is well regarded (Strauss and Corbin 1994; Barber 2008). It puts forward an integrated set of explanatory propositions validated by a thorough inductive analysis (Corbin and Strauss 1990) and can inform practitioners about how to plan, implement and review the efficacy of their practices (Schalock, Bonham and Verdugo 2008). Consequently the starting point for the study was the choice of grounded theory as the facilitative inquiry paradigm. The broad purpose of the study was to build knowledge, understanding and theory about coming to know individuals with PMID. Lyons regarded symbolic interactionism (see e.g. Blumer 1969; Charon 2009) as the most appropriate theoretical perspective and he adopted ethnographic research (see e.g. Edgerton 1996) because it was synchronous with this. Finally, a modified Straussian grounded theory emerged as the most appropriate research methodology.

This methodology directed the analysis of the emergent data and the construction of the conceptual categories and storyline of the final grounded theory. Diagram 1 is a graphical précis and the following summative explanation refers to this. The core process of this methodology is data analysis, involving open, axial and selective coding. This commences with open coding, followed soon after and simultaneously by axial coding, which continues until selective coding is implemented. Constant questioning and comparative analysis drive this process. Theoretical sampling, informed by the core process, directs the nature and purpose of data gathering. Data 
gathering, memoing and diagramming cease when theoretical saturation is achieved. Three analytic foci direct the coding: coding for concepts, coding for process, and coding for the paradigm (the matrix). A range of analytic tools are deployed to facilitate the core process including primarily an initial microanalysis and the paradigm; along with the subsequent strategic use of questioning, mini-analysis, the flip-flop technique, systematic comparisons and waving the red flag. (These tools are explained in Strauss and Corbin 1994.)

The core process delivers progressive and accumulative outputs. During open coding these are concepts and categories with properties and dimensions. During axial coding these are subcategories with properties and dimensions, and interrelationships between categories and subcategories. Finally, during selective coding, these outputs are major categories and the central category, and their interrelationships. Subsequent to theoretical saturation, the penultimate output is a storyline that scaffolds the final grounded theory. Progress through this process is determined by staged reviews of output density and completeness.

Regular Straussian grounded theory methodology is summarised in Strauss and Corbin (1994) and comprehensively explained in Strauss and Corbin (1998). Our modifications were primarily around the differentially weighted use of the various analytical tools to account for the severe communicative disabilities of the participating children and young people with PIMD, and the presentation of the theory and the data from the observations, interviews and literature in conceptual categories. 


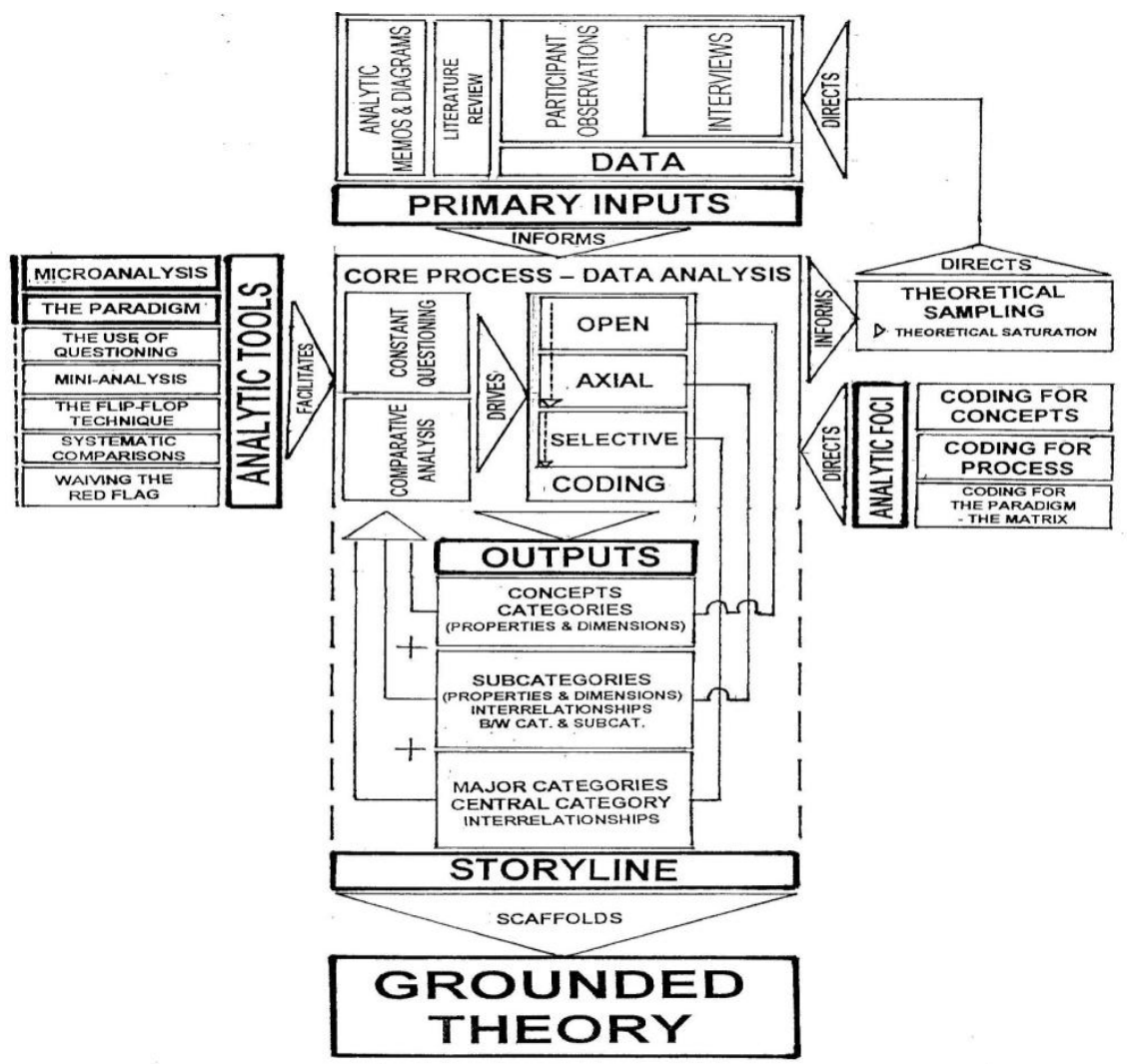

Figure 1: Lyons' modified Straussian grounded theory methodology

A grounded theory on subjective wellbeing for children and young people with PIMD

The central category, four main categories and fourteen subcategories

\section{Central category}

Doing enjoyable things. SWB for these children is primarily about doing enjoyable things. It's about being engaged with people who, and in activities that, are needed, wanted, liked and/or preferred.

\section{Main category 1: Just like other children but personal}

SWB is the same for all children, but for these children it is often expressed in very personal ways. 
Subcategories:

- Wellbeing discourses. SWB does not make sense for these children, but quality of life and happiness do.

- Disability discourses. Disability is understood in different ways. Unfamiliar others often only see disability in these children, and not how they are feeling, learning and growing.

- Childhood and adulthood. These children are developing. They have a future, but they live in the here and now.

- Individuality. These children are individuals, and have their own characters and expressions.

\section{Main category 2: Happiness and contentment}

Life satisfaction is about feeling both happiness and contentment.

Subcategories:

- Day-by-day. Happiness and contentment should be experienced daily, and life lived one day at a time.

- Just taking it all in. Contentment can be just taking it all in.

- Balance. Happiness and contentment is about personal balance.

\section{Main category 3: Comfort and wellbeing}

Life satisfaction is about feeling both comfort and wellbeing.

Subcategories:

- Physical health. Relief from acute/chronic pain is a prerequisite.

- Daily wellbeing. Just having a good day is valued.

- Belonging. Relationships are central.

\section{Main category 4: Favourite things}

Life satisfaction is doing and having favourite things.

Subcategories:

- $\quad$ Being with others, caring and sharing.

- Special things, doing special things with special people.

- Water play. Playing with water is freedom, fun and belonging.

- Fun, having a wicked sense of humour!

\section{The storyline}

The central category 'Doing enjoyable things' posits that SWB for these children is primarily about doing enjoyable things. It is about being engaged in activities that, and with people who, are needed, wanted, liked and/or preferred. Doing enjoyable things usually requires engagement with others, as these children have a limited capacity to engage in activities on their own. Communication, through 
intersubjectivity and understanding, opens doorways to doing enjoyable things. Parents and other primary carers emphasise doing enjoyable things that are wanted and liked, whereas school staff emphasise doing things that are needed. This central category is widely referred to in the literature as a key characteristic of (and even prerequisite to) a life of quality, SWB and happiness.

Five themes, each with three positions, emerged from the literature review. These positions were that each theme was either a right, a necessity and/or beneficial. Theme 1 'Doing' included references to meaningful and creative activity, purposeful involvement, stimulation, play and leisure. Theme 2 'Doing with others' refers specifically to doing with other people, particularly adults. Theme 3 'Enjoyment' centred on enjoyment that might arise from thinking (reminiscing and imagining), doing and/or doing with others. Theme 4 'Interaction' centred on interrelationships between children with PIMD and others. Theme 5 'Choice' included reference to choice, decision making, autonomy and empowerment.

The first main category 'Just like other children but personal' posits that SWB is the same for all children, but for these children it is often expressed in very personal ways. Children with PIMD were the focus of this study, but children and young people with severe intellectual disabilities also participated. SWB was expressed in both similar and obvious, and idiosyncratic and subtle, ways. These children tended to use more subtle and personal expressions. Seven themes emerged from the literature: growth and development; relationships are the same; experiencing feelings is the same; expressing feelings is the same; unhappiness and dissatisfaction are the same; ethics and rights are the same; and expressing feelings is also unique.

The second main category 'Happiness and contentment' posits that SWB is about feeling both happiness and contentment. For these children, being happy and contented is what SWB is really all about, and their communication partners not only wanted them to be so but viewed their happiness to be a right of childhood. Discerning happiness in these children is generally not problematic but, because these children often live with acute and chronic pain, discerning contentment is frequently problematic. Communication partners found it hard to discern between contentment and boredom, and it took them more time to get to know children with more disablement. Being contented is more a state of being rather than doing, and can be 'just taking it all in'.

Six themes emerged from the literature: Theme 1: The nature of happiness and contentment; Theme 2: Assessing happiness and contentment; Theme 3: The importance of happiness and contentment; Theme 4: Sources of happiness and contentment; Theme 5: The pursuit of happiness and contentment; and Theme 6: Research on happiness and contentment for people with intellectual disabilities.

The third main category 'Comfort and wellbeing' posits that SWB is about feeling both comfort and wellbeing. For these children, comfort is primarily about physical comfort, but also about emotional comfort. Wellbeing is primarily about emotional wellbeing. Physical health, daily wellbeing and belonging seem to inform an 
understanding of the feelings of comfort and wellbeing for these children and are comparatively easy to discern through mood, disposition and degrees of relaxation.

Two themes emerged from the literature: Theme 1: Comfort and wellbeing are important, and Theme 2: Comfort and wellbeing are interrelated. Physical and emotional comfort and wellbeing are principal components of theories and models about quality of life relating to children and young people with (intellectual) disabilities. Comfort and wellbeing are also interrelated. That is, in general, comfort and wellbeing enhance each other, and specifically physical comfort and wellbeing and emotional comfort and wellbeing enhance each other.

The fourth main category 'Favourite things' posits that SWB is doing and having favourite things. This fourth main category has four subcategories: being with others; special things; water play; and fun. These subcategories bring uniqueness to this theory, by putting forward aspects that are clearly particular to the participating children. Three themes emerged from the literature: Theme 1: Preference assessment for learning, Theme 2: Preference assessment for enjoyment; and Theme 3: Just leisure.

The interrelationships between the nineteen categories of this theory are complex. The metaphor of a 'mobile' is illustrative, wherein SWB may be said to be best when the mobile is in balance, that is, when the categories and interrelationships between them result in a personal balance for the individual with PIMD. (See Lyons 2003 for a detailed explanation of these interrelationships.)

\section{Discussion}

Lyons' grounded theory offers a comprehensive and research-based explanation of the nature of SWB for children and young people with PIMD. This responds to the challenge to conceptualise this phenomenon for this group of students and informs and advances a continuing research agenda to define it and make it 'measureable'. Once this is achieved governments, education systems, communities, schools and parents should be collectively empowered to improve student wellbeing for this quite marginalised and challenged group of students. This in turn would contribute to the broad, 'non-academic' outcome imperatives put upon schools. Given the contemporary and ongoing debates about the nature of these non-academic outcomes and the substantial professional and community interest in the likely nature of the impending Australian Curriculum (arising out of the 2008 'Melbourne Declaration' on educational goals for all Australian school students), this research has particular and timely relevance.

What is implicitly (if not explicitly) evident is that student wellbeing for those with PIMD (as described briefly in this paper) is both the same as and different to that of all other students. A review of the categories indicates this. For example, the central category 'Doing enjoyable things' would be widely regarded to apply to all children and young people. The first main category 'Just like other children but personal' emphasises this similarity while recognising the communicative idiosyncrasies (differences) and challenges facing students with PIMD. Its four subcategories are equally suggestive. The second main category 'Happiness and contentment' 
emphasises the prominent place of happiness and contentment for children and young people with PIMD. This hardly differs for others; parents and important others almost invariably articulate their wishes for their children to 'be happy' both now and in the future, and emphasise the place of school in contributing to this in the short and longer terms. Its three subcategories are similarly suggestive. The third main category 'Comfort and wellbeing' emphasises the importance of physical and emotional wellbeing for children with PIMD. This similarly applies to other children, the difference being the substantial challenges these children face with respect to physical impairment and pain, and social and emotional 'distancing' due to their communicative impairments. Its three subcategories explicate these similarities and differences. The fourth main category 'Favourite things' and its four subcategories also reveal similarities and differences. All children and young people have and do 'favourite things' but those with PIMD have very special things, that is, special ways of relating to and engaging with special others. This difference arises again because of their cognitive and communicative impairments and challenges; they have to develop special ways to overcome these challenges that others rarely face. Furthermore children and young people generally enjoy water play and fun but for those with PIMD water play and fun are favourites!

Lyons' theory also informs contemporary research efforts into understanding how communication partners come to know individuals with PIMD (see e.g. Forster 2011) and informs the continuing development of the Life Satisfaction Matrix (Lyons 2005), a procedure for improving SWB for persons with PIMD. The matrix procedure for ascertaining (but not measuring) and improving SWB for these individuals is applicable across home, school and community settings and is pedagogically consistent with other evidence-based practices frequently employed in the field like intensive interaction, person-centred planning and assessments of support services that refer to quality of life. The matrix procedure emphasises collaborative practices and requires the proactive involvement of parents/carers and supportive colleagues.

So how can schools and families collaborate to improve the wellbeing of children and young people with PIMD? First they could review their current conceptualisations of student wellbeing and investigate alternative, facilitative research-based conceptualisations that might better inform policy and practice development. Second they could then review and possibly modify curriculum goals and intended outcomes for students with PIMD (and consequently their curriculum content and assessment and pedagogical practices) to improve academic and nonacademic educational outcomes for these students. Third they could investigate the implementation of the Life Satisfaction Matrix as one other procedure for improving the SWB of these children and young people.

\section{Conclusions}

Lyons' theory of SWB for children and young people with PIMD offers one research-based explanation of the nature of this phenomenon and responds to the challenge of conceptualisation. All of the children and young people who participated in the study were school students and the field data that became the 
basis of the theory was sourced from their parents and other family members, teachers and other school support staff.

The 'generic' phenomenon of SWB is implicitly and explicitly related to the more context-specific phenomenon of student wellbeing. Arguably then improved SWB equates to improved student wellbeing.

So student wellbeing for those with PIMD: is it the same, or same but different? The nature of student wellbeing, like subjective wellbeing, is much the same for all students but there are differences arising from the very individual needs and qualities of students with PIMD. As educators we need to ascertain what is the same and develop our curriculum pedagogy and assessment principles and practices accordingly. We also need to ascertain what is different in order to differentiate our curriculum pedagogy and assessment practices accordingly. This grounded theory and the continuing research agenda that is (at least in part) informed by it have potential to inform this development.

\section{References}

Anderson, P 2004, 'What makes a difference? How measuring the non-academic outcomes of schooling can help guide school practice', paper presented at the 2004 Supporting Student Wellbeing Conference, Adelaide, South Australia, 24-26 October.

Arthur-Kelly, M, Foreman, P, Bennett, D and Pascoe, S 2008, 'Interaction, inclusion and students with profound and multiple disabilities: towards an agenda for research and practice', Journal of Research in Special Education Needs, vol. 8 , no. 3, pp. 161-168.

Australian Association of Special Education 2011, 'President's report', AASE (New South Wales Chapter) Newsletter, April.

Australian Curriculum Assessment and Reporting Authority 2010, ACARA's response to the consultation feedback on the draft of the Australian Curriculum, ACARA, Canberra.

Barber, M 2008, 'Using intensive interaction to add to the palette of interactive possibilities in teacher-pupil communication', European Journal of Special Education, vol. 23, no. 4, pp. 10-18.

Bayliss, P 2005, 'Peter, Katie and Billy: including children with significant support needs', paper presented at the 2005 ISEC Conference, Glasgow, Scotland, August.

Blumer, H 1969, Symbolic interactionism: perspective and method, Prentice-Hall, Englewood Cliffs, NJ. 
Carnaby, S 2004, People with profound and multiple learning disabilities: a review of research about their lives, MENCAP, London.

Charon, JM 2009, Symbolic interactionism: an introduction, an interpretation, an integration, 10th ed., Prentice Hall, Boston.

Corbin, J and Strauss, A 1990, 'Grounded theory research: procedures, canons, and evaluative criteria', Qualitative Sociology, vol. 13, no. 1, pp. 3-21.

Cummins, R 2002, 'Maintaining life satisfaction: the role of positive cognitive bias', Journal of Happiness Studies, vol. 3, no. 1, pp. 37-69.

Cummins, R, Lau, A, Davey, G and McGillivray, J 2010, 'Measuring subjective wellbeing: the Personal Wellbeing Index - Intellectual Disability' in Enhancing the quality of life of people with intellectual disabilities, ed. $\mathrm{R}$ Kober, Springer, London, pp. 33-46.

Edgerton, RB 1996, 'A longitudinal-ethnographic research perspective on quality of life', in Quality of Life. Volume I: Conceptualization and Measurement, ed. RL Schalock, AAMR, Washington, DC, pp. 83-91.

Felce, D and Perry, J 1996, 'Assessment of quality of life', in Quality of Life. Volume I: Conceptualization and Measurement, ed. RL Schalock, AAMR, Washington, DC, pp. 63-72.

Felce, D and Perry, J 2005, 'Quality of life: issues of objective and subjective measurement', Giornale Italiano delle Disabilita, vol. 5, no. 1, pp. 3-14.

Foreman, P and Arthur-Kelly, M 2005, 'Alertness levels and communication involvement in students with the most severe multiple disabilities in Australian classrooms: effects of short teacher training programs', paper presented at the 2005 ISEC Conference, Glasgow, Scotland, August.

Forster, M 2004, 'Measuring the social outcomes of schooling: what does ACER's research tell us?', paper presented at the 2004 Supporting Student Wellbeing Conference, Adelaide, South Australia, 24-26 October.

Forster, S 2011, Affect attunement in communicative interactions between adults with profound intellectual and multiple disabilities and support workers, $\mathrm{PhD}$ thesis, Monash University, Australia.

Fraillon, J 2004, Measuring student well-being in the context of Australian schooling: discussion paper, ACER, Melbourne.

Goldbart, J and Caton, S 2010, Communication and people with the most complex needs: what works and why this is essential, MENCAP, London. 
Goode, D 1984, 'Socially produced identities, intimacy and the problem of competence among the retarded', in Special education and social interests, ed. L Barton and S Tomlinson, Croom Helm, London, pp. 228-248.

Goode, D 1990, 'The world of the congenitally deaf-blind: towards the grounds for achieving human understanding', in Mental retardation: a phenomenological approach, ed. J Jacobs, Temple University Press, Philadelphia, PN, pp. 381396.

Halpern, A 1993, 'Quality of life as a conceptual framework for evaluating transition outcomes', Exceptional Children, vol. 59, no. 6, pp. 486-498.

Hamilton, P 2004, 'Using evidence to drive system change to improve student wellbeing', paper presented at the 2004 Supporting Student Wellbeing Conference, Adelaide, SA, 24-26 October.

Hewett, D 2009, 'Intensive interaction: priorities and principles for teaching communication to pupils with PIMD', paper presented at the 2009 CCEA Conference, Connemara, Ireland, October.

Hogg, J 2007, 'Complex needs and complex solutions: the challenge of profound intellectual and multiple disabilities', Journal of Policy and Practice in Intellectual Disabilities, vol. 4, no. 2, pp. 4-14.

Killen, R 2005, Programming and assessment for quality teaching and learning, Thomson, Melbourne.

Lancioni, G, O'Reilly, M, Campodonico, F and Mantini, M 2002, 'Increasing indices of happiness and positive engagement in persons with profound multiple disabilities', Journal of Developmental and Physical Disabilities, vol. 14, no. 3, pp. 231-237.

Lyons, G 2003, Life satisfaction for children with profound multiple disabilities, $\mathrm{PhD}$ thesis, University of Newcastle, Australia.

Lyons, G 2005, 'The Life Satisfaction Matrix: an instrument and procedure for assessing the subjective quality of life of individuals with profound multiple disabilities', Journal of Intellectual Disability Research, vol. 49, no. 10, pp. 4-8.

Lyons, G 2010, 'Quality of life for persons with intellectual disabilities: a review of the literature', in Enhancing the quality of life of people with intellectual disabilities, ed. R Kober, Springer, New York, pp. 73-125.

Lyons, G and Cassebohm, M 2010, 'Life satisfaction for children with profound intellectual and multiple disabilities', in Enhancing the quality of life of people with intellectual disabilities, ed. R Kober, Springer, New York, pp. 183-204. 
Maes, B 2002, 'The significance of the relationship between direct care staff and persons with disabilities for quality of care and quality of life', paper presented at the 2002 Inaugural IASSID Europe Quadrennial Conference, Dublin, Ireland, 12-15 June.

McGaw, B 2010, Statement from ACARA, ACARA, Canberra.

Nakken, H and Vlaskamp, C 2007, ‘A need for a taxonomy for profound intellectual and multiple disabilities', Journal of Policy and Practice in Intellectual Disabilities, vol. 4, no. 2, pp. 4-12.

Noble, T and Wyatt, T 2008, Scoping study into approaches to student wellbeing, Australian Catholic University and Erebus International, Sydney.

Petitpierre, G, Wolf, D, Dietrich, A, Benz, M and Adler, J 2007, 'Integration of education and care given to children with profound multiple disabilities in Switzerland', Journal of Policy and Practice in Intellectual Disabilities, vol. 4, no. 2, pp. 11-23.

Petry, K, Maes, B and Vlaskamp, C 2009, 'Measuring the quality of life of people with profound multiple disabilities using the QOL-PMD: first results', Research in Developmental Disabilities, vol. 30, pp. 12-20.

Pollard, EL and Lee, PD 2003, 'Child well-being: a systematic review of the literature', Social Indicators Research, vol. 61, no. 1, pp. 59-65.

Ryan, RS and Travis, JW 1998, The wellness workbook, Ten Speed Press, California.

Schalock, RL 1990, 'Attempts to conceptualize and measure quality of life' in Quality of life: perspectives and issues, ed. RL Schalock and MJ Begab, AAMR, Washington, DC, pp. 141-148.

Schalock, RL, Bonham, GS and Verdugo, MA 2008, 'The conceptualization and measurement of quality of life: implications for program planning and evaluation in the field of intellectual disabilities', Evaluation and Program Planning, vol. 31, no. 2, pp. 181-190.

Singh, N, Lancioni, GE, Winton, AS, Wahler, RG, Singh, J and Sage, M 2004, 'Mindful caregiving increases happiness among individuals with profound multiple disabilities', Research in Developmental Disabilities, vol. 25, pp. 12-24.

Strauss, A and Corbin, J 1994, 'Grounded theory methodology: an overview' in Handbook of Qualitative Research, ed. NK Denzin and YS Lincoln, Sage, Thousand Oaks, CA, pp. 273-285. 
Strauss, A and Corbin, J 1998, Basics of qualitative research: techniques and procedures for developing grounded theory, 2nd ed., Sage, Newbury Park, CA.

Vos, P, De Cock, P, Petry, K, Van Den Noorgate, W and Maes, B 2010, 'What makes them feel like they do? Investigating subjective well-being in people with severe and profound disabilities', Research in Developmental Disabilities, vol. 31, pp. 1623-1633.

Ware, J and Donnelly, V 2004, 'Assessment for learning for pupils with PMLD: the ACCAC insight project', PMDL Link, vol 6, no. 3, pp. 12-18.

Warren, SF, Brady, NC and Fey, ME 2004, 'Communication and language: research design and measurement issues' in International handbook of research in intellectual disabilities, ed. E Emerson, C Hatton, AS Thompson and T Parmenter, John Wiley \& Sons, Chichester, UK, pp. 385-405.

1 Electronic copies of Lyons (2003) are available from the author. 